\title{
Optimization Model using WASP-IV for Pakistan's Power Plants Generation Expansion Plan
}

\author{
Engr. Muhammad Fahad Shinwari ${ }^{1}$, Engr. Muhammad Latif ${ }^{2}$, Naveed Ahmed ${ }^{3}$ \\ , Hassan Humayun ${ }^{4}$, Dr. I.M Qureshi ${ }^{5}$, Dr. Ihsan ul Haq ${ }^{6}$ and Dr. Yasin \\ Chohan ${ }^{7}$. \\ ${ }^{1}$ (Faculty of Electronics Engineering/International Islamic University, Islamabad, Pakistan) \\ ${ }^{2}$ (Energy Wing, Planning Commission / Pakistan Atomic Energy Commission, Pakistan)
}

\begin{abstract}
This paper introduces novel framework for the modeling of hydro and thermal power plants generation system expansion plan for Pakistan. The modeling is achieved by using WASP-IV (Wien Automatic System Planning) model. It consists of seven modules. Each module determines different outputs with their respective inputs. Electricity demand is rapidly increasing as the population rises. The Electricity demand increased with devastating rate of 7.8\% per year from 2003 to 2011. The installed capacity is not fulfilling the electricity demand. An mandatory generation mix supply is required for the time period 2011-2030. The Power Expansion Planning is done on generation level. In 2011, electricity demand raised to 25,400 MW. In this paper load is forecasted with standard regression method. It helps in prediction of different types of loads. Then the Load Duration Curves generated are normalized against capacity factor at which power plant is operated. Further several necessary parameters are evaluated which are involved in generation expansion plan. Moreover, the selection of plants is achieved through screening curves. It allow us to know the most economical plants for base load, base load and peak load at different capacity factors. Screening curve is created by finding annualized cost, capital cost, heat rate, fuel rate and fixed costs for each plant. Thus by comparison, it helps us in a more convenient way to select the most feasible plant in correspondence of economical and fuel constraints. The result illustrates the Optimized Cost of Generation Plan, Generation Mix Supply for Pakistan (year 2030). It emphasizes on Investment and Production Costs (\$ US Million), Fuel requirement and their costs, Operation and Maintenance Costs, and Loss of Load Probability. In the end, least cost financial plan for the whole time period is determined.
\end{abstract}

Keywords: Screening Curves, Capacity Factors, Heat Rate, Generation Mix Supply, Load Duration Curves, Loss of Load Probabilility.

\section{Introduction}

The modeling is achieved by using WASP-IV (Wien Automatic System Planning) model. It consists of seven modules. Each module determines different outputs with their respective inputs. The proposed power system expansion planning is for year 2011-12 to 2030-31. Pakistan is blessed with conventional and nonconventional indigenous energy resources. But there still persists immense amount of energy crisis in Pakistan as the population rises. Electricity Demand is rapidly increasing. The Electricity demand increased with devastating rate of $7.8 \%$ per year from 2003 to 2011. The installed capacity is not fulfilling the electricity demand. Major of installed capacity relies on the hydro power. Hydro contributes nearly $30 \%$ of total installed system capacity. But the Hydro depends on seasonal variability. So there should be proper generation mix supply for the mentioned time period. The Power Expansion Planning is done on Generation level. In 2011, electricity demand raised to 25,400 MW. Power System Expansion plan focuses on long- term and short term requirements. The Power System expansion plan is based on satisfying reliability criteria. Reliability criteria is satisfied by Loss of Load Probability. It shows the risk associated with having insufficient generation to meet the forecasted load demand. To forecast different types of loads, load is divided into three types of categories i-e Base load, peak load and intermediate load. With the help of Load duration curves we can distinguish Base load, peak load and intermediate loads. Load Duration Curve portrays maximum and minimum load demands. Category wise break down of projected load is achieved for different sectors. Further selection of plants is achieved through screening curves. Thus, allowing us to know the most economical plants for base load, intermediate load and peak load for a certain time period. Screening Curve involves the capacity factor for each plant. Screening curve is created by finding annualized cost, capital cost, heat rate, fuel rate and fixed costs for each plant. These screening curves are compared with Load Duration Curves. Thus by comparison, it helps us in a more convenient way to select the most feasible plant in accordance of their economical prices and environmental constraints. Moreover the projections of screening curves are drawn on the load duration curves to analyze them with respect to capacity factor. The result illustrates the Optimized Cost of Generation Plan. It 
emphasizes on Investment and Production Costs (\$US Million), Fuel costs, Operation and Maintenance Costs, Loss of Load Probability and un-served energy charges. At last financial plan is prepared for the whole time period.

\section{Optimization Model}

Modeling is done within certain constraints. There are numerous modeling techniques, as mentioned in [3], [4] and [5]. But the optimization model for power generation system expansion plan for Pakistan (20112030) is discussed below:

\section{I Proposed Optimization Architecture}

The proposed flow chart in Fig.1 illustrates the data collection process globally and locally. Then optimized model is prepared for hydro and thermal power plants. To carry out research on my desired problem, a methodology is selected with respect to the generation expansion constraints. The collected and forecasted data is given to WASP-IV modules [6]. They generate output results until optimization is achieved through the help of screening curves and dynamic programming [7]. Further the optimized results are analyzed and a generation expansion plan is prepared.

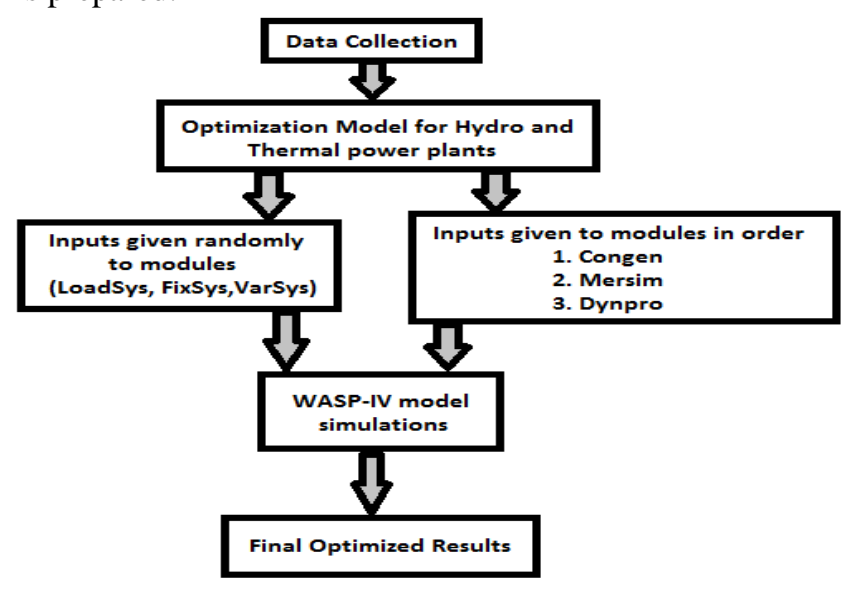

Fig. 1. Flow Chart for Power Generation Expansion Plan

\section{II.II Methodology}

WASP-IV (Wien Automatic System Planning) model is an power generation expansion tool, used to model a hydro and thermal plants. It has been prepared by IAEA (International Atomic Energy Agency) [6] and provided to many for power system expansion planning studies.

WASP IV consists of the following seven modules as given below:

1. LOADSYS: A program that describes the load duration curves and forecast the peak loads for the system for the system.

2. FIXSYS: A program that describes the existing power system and all future additions and retirements which are to be firmly scheduled.

3. VARSYS: It's a program that describes the candidate plants (which are to be added in future) which might be used to expand the power system.

4. CONGEN : A program which is used to generate all possible year to year alternative combinations of expansion system, the alternative expansion configurations are combination of plants on economical and environmental basis.

5. MERSIM: It is used to determine whether a particular configuration has been simulated, if it's not simulated than it merges the system and calculates the production costs, ENS and system reliability denoted by LOLP for each configuration.

6. DYNPRO: It is a program to determine the optimum cost schedule (Optimal trajectory path) by dynamic programming for adding new units to the system over the time period of interest.

7. REPROBAT: It's the last module that summarizes the input data and also the results of the study and the cash flow requirements of the optimum solution [6].

In WASP-IV model inputs are given by user to each module, further each module generates different outputs on the basis of the inputs given to them. 


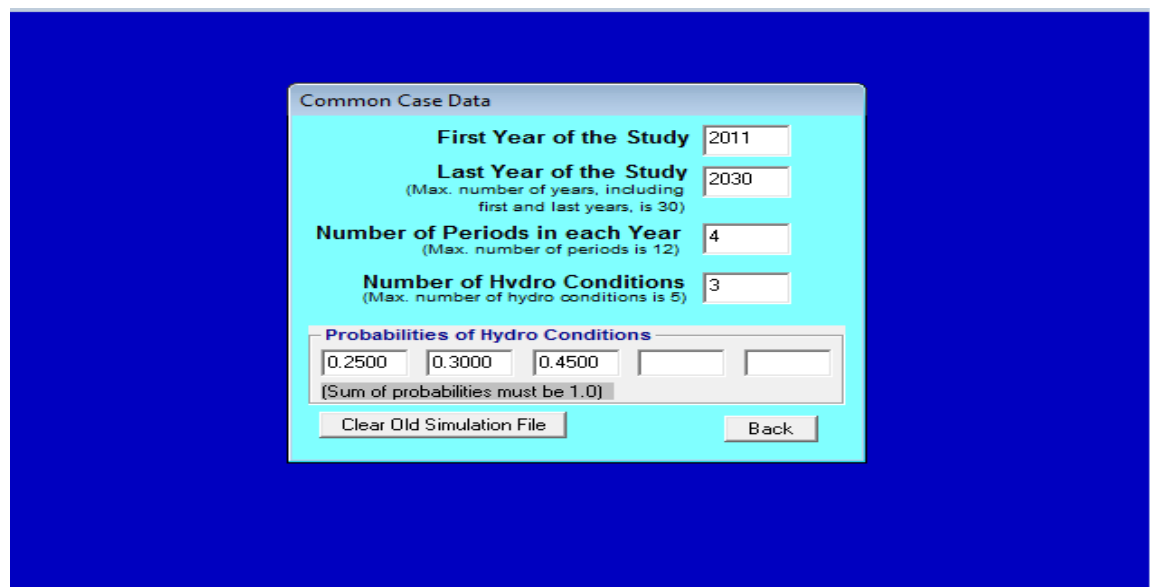

Fig.1 WASP-IV module defining expansion period.

As there are seven modules in WASP-IV, each module has its input and output with defined constraints by user. First of all we define the first year (from where our plan starts) and last year (the year at which expansion would be finished). The first year and last year defined here are 2011 and 2030. The number of periods in each year represents the division of one year into small intervals called "periods". It can be described by user. Then we define number of Hydro conditions for addition of hydro plants. The number of probabilities of Hydro condition represents the hydro condition in a specified period. It's the data that is required for initialization. Then LoadSys module is loaded with the inputs.

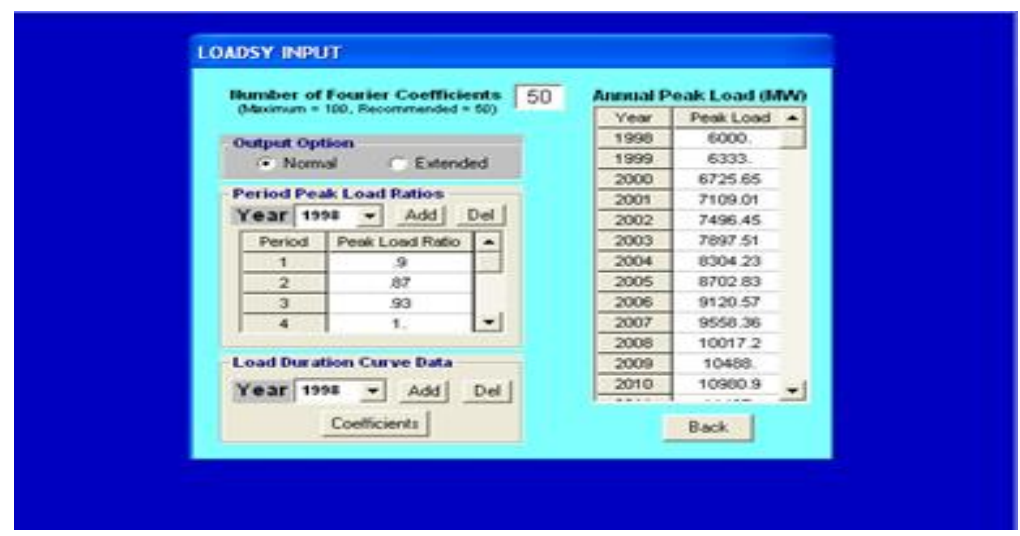

Fig.2 WASP-IV LoadSys Input Module

As shown in Fig.2, the LoadSys module gives us load duration curves. The inputs for loadsys are the number of Fourier coefficients for the construction of load duration curves. Annual peak load demand in Mega Watt and period peak load ratios.

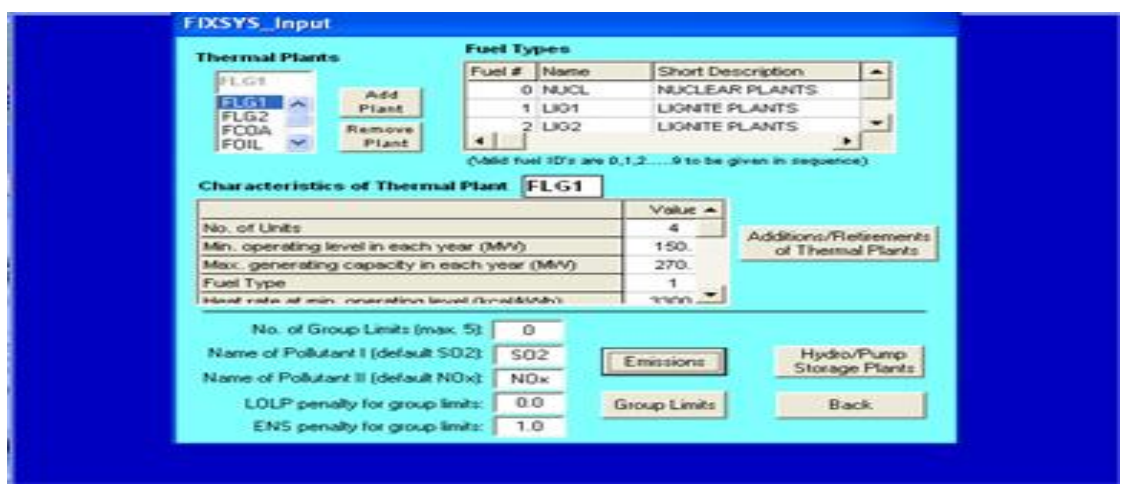

Fig.3 WASP-IV FixSys Input Module

Fig.3 shows the FixSys module describes the addition of thermal and hydro plants. Here coal, hydro, Combined Cycle, nuclear and gas turbines are added. And also information of additions and retirements of each plant in the desired year is given here. The thermal plants give group limitations of up-to 5 . 


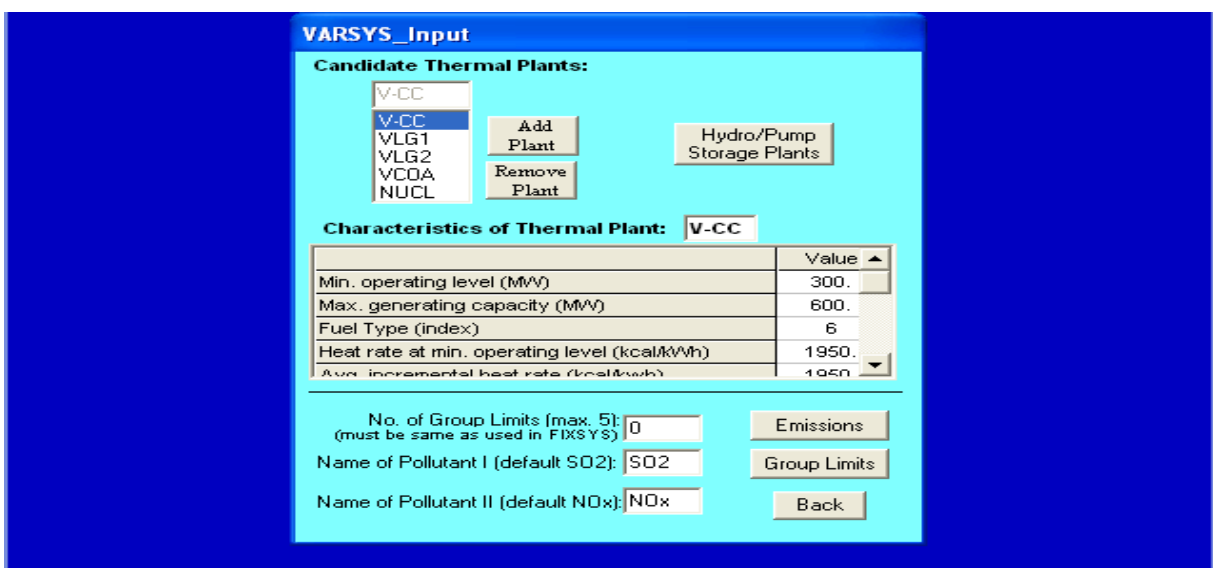

Fig.4 WASP-IV VarSys Input Module

The characteristics of VarSys plants are emissions, group limit, minimum operating level, maximum generation capacity, fuel type and heat rate. etc

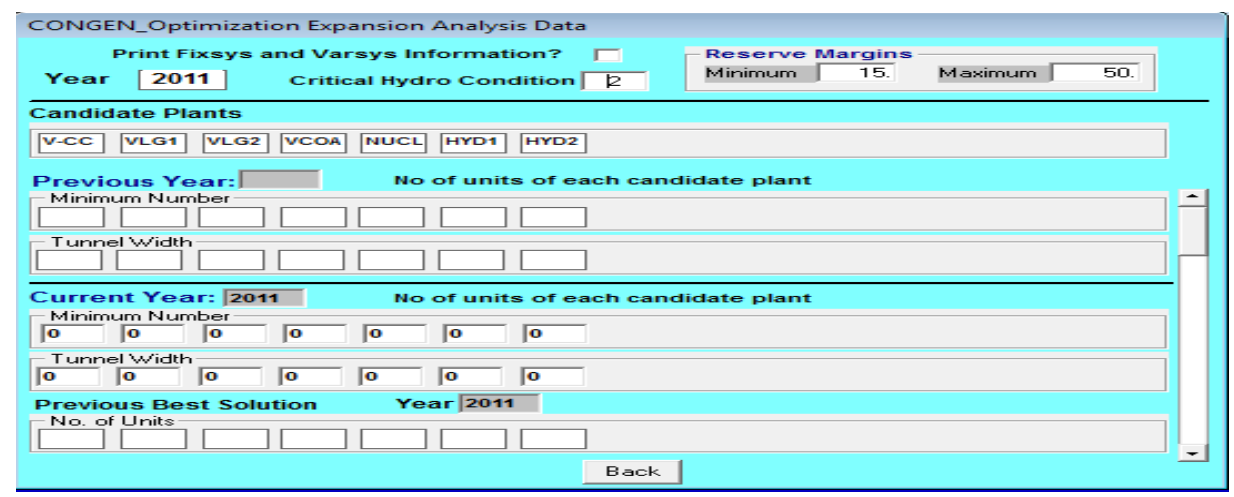

Fig.5 WASP-IV ConGen Input Module

Loading of input modules (loadsys, fixsys and varsys) of WASP-IV model with randomized order we define tunnel width in ConGen module. The addition of candidate plants (to be added in future are represented by "+") show future addition of plant in the desired year of expansion and the retirement of plants in future shows that plant would be expired in the mentioned year of expansion. (retirement of plants are represented by "_"). Tunnel width is the width defined for number of alternative configurations generated during the desired period of 2011-2030. The more tunnel width is less optimized and efficient model would be designed. Because it consider the plants lying beyond the constraints defined by user. So tunnel width must be less. And reserve margins are spinning reserves to meet the load in case of forced outages.

After the configurations are generated, the input of the above mentioned modules are merged and simulated with MerSim module of WASP-IV.

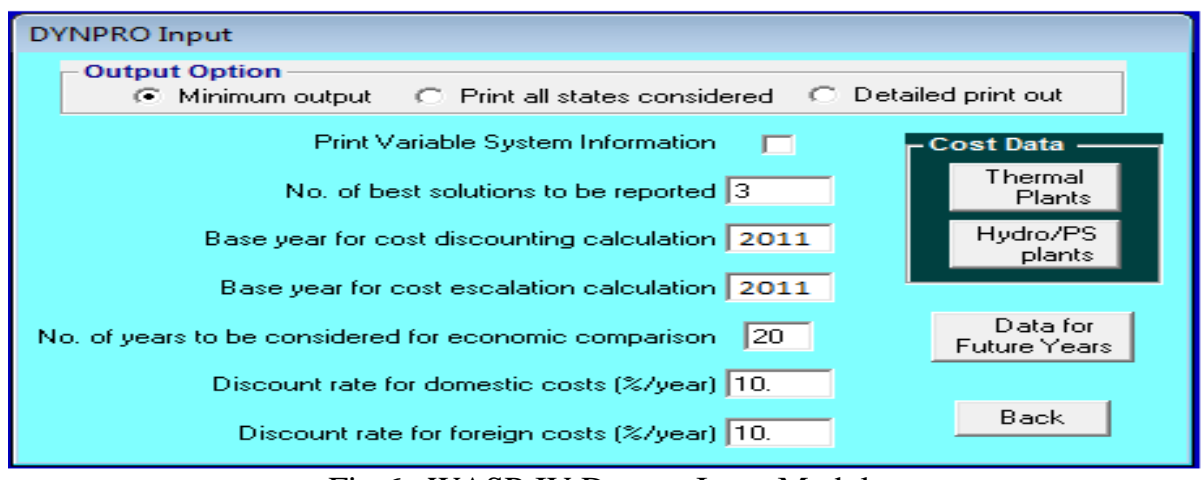

Fig.6 WASP-IV Dynpro Input Module

Moreover, in DynPro module, inputs like no. of best solutions, base year for cost discounting calculation, base year for cost discounting calculation, cost data for thermal plants and hydro plants, data for 
future are taken in account with Discount Rates for domestic costs per year and Discount rate for foreign costs per year. It provides optimal trajectory path using Dynamic programming. It further provides least cost expansion plan.

The desired necessary data collection is carried out from internet source corresponding to their inputs ie; heat rate, fuel cost, Operation and Maintenance Cost, heat value, Capital Cost, variable cost, fixed cost, domestic and foreign currency rates etc

The cost function to be optimized in WASP-IV is given by (1), the basic minimized cost function is represented depending on certain constraints as described below:

$$
B_{j}=\sum_{t=1}^{T}\left[\overline{I_{j, t}}-\overline{S_{j, t}}+\overline{\mathrm{F}_{j, t}}+\overline{\mathrm{L}_{j, t}}+\overline{\mathrm{M}_{\mathrm{j}, \mathrm{t}}}+\overline{\mathrm{O}_{\mathrm{j}, \mathrm{t}}}\right]
$$

The function in (1) shows capital investment costs (I), fuel costs (F), salvage value of investment costs (S), fuel inventory costs (L), non-fuel operation, maintenance costs $(\mathrm{M})$ and cost of the energy not served (O). Those functions are further dependant on other variable factors as discussed in [6].

The merged data is simulated, and then data is given by user to different modules and WASP -IV generates alternative expansion configurations of different plants for each period defined and in such a way that user gets optimized least cost expansion plan with many other useful outputs such as emission by plants, Energy not Served (ENS, Loss of Load Probability, Optimized Financial Plan, Load Duration Curves etc.

The above methodology implemented, is a long term power generation expansion planning (GEP). In monopoly electricity markets [15], WASP-IV is mainly used for electricity planning. In a monopoly market the main theme is to meet power demand with Energy Not Served (ENS) at a minimum cost, but in a pool power market [8] the main aim is to meet power demand at a reduced ENS and wholesale electricity price. But in all scenarios, all things being equal means that supply should always meet demand at the least cost [9].

The seven modular program WASP-IV can determine the optimal GEP for a power system over a period of 30 years, within the system planning constraints, based on total minimum discounted system costs and several constraints [16].

\section{Probabilistic Dispatches: Necessary Parameters}

To carry out expansion, one requires certain parameters. Those parameters are involved in evolving the expansion plan.

\section{I Required Fuel and their Prices for Screening Curves}

Fuel Prices are necessary, as they are required for screening curves. The fuel costs were taken from the Pakistan Energy Yearbook 2011[17], the International Energy Agency [18], Energy Information Administration [20] and Inter State Gas Systems (ISGS) [19], the prices were adjusted relevant to 2011 prices [21]. Before starting generation expansion, one needs to find those fuel costs for calculating certain parameter. Fuel costs are shown in Table. 1.

TABLE. 1

\begin{tabular}{|c|c|c|c|c|c|c|}
\hline Fuel & $\begin{array}{c}\text { Unit } \\
\text { forfuel }\end{array}$ & $\begin{array}{l}\text { Year } \\
2011\end{array}$ & $\begin{array}{l}\text { Year } \\
2014\end{array}$ & $\begin{array}{l}\text { Year } \\
2019\end{array}$ & $\begin{array}{l}\text { Year } \\
2024\end{array}$ & $\begin{array}{l}\text { Year } \\
2030\end{array}$ \\
\hline $\begin{array}{l}\text { Nuclear Fuel } \\
\text { (U308) }\end{array}$ & $\$ / I b$ & 64 & 80 & 60 & 60 & 60 \\
\hline $\begin{array}{l}\text { Thar Coal } \\
\text { (Mined) }\end{array}$ & $\$ / M T$ & 44 & 44 & 44 & 44 & 44 \\
\hline $\begin{array}{l}\text { Imported } \\
\text { Natural Gas }\end{array}$ & \$/MMBtu & 10 & 11 & 12 & 13 & 13 \\
\hline Imported LNG & $\$ / M M B t u$ & 10 & 13 & 14 & 15 & 17 \\
\hline $\begin{array}{l}\text { Furnace Oil } \\
\text { (HSFO) }\end{array}$ & $\$ / \mathrm{MT}$ & 509 & 511 & 586 & 622 & 668 \\
\hline $\begin{array}{l}\text { Furnace Oil } \\
\text { (LSFO) }\end{array}$ & $\$ / M T$ & 560 & 562 & 644 & 685 & 735 \\
\hline Diesel & \$/Liter & 0.79 & 0.83 & 0.95 & 1.01 & 1.08 \\
\hline Imported Coal & \$/MT & 128 & 147 & 165 & 151 & 140 \\
\hline $\begin{array}{l}\text { Imported Crude } \\
\text { Oil }\end{array}$ & $\$ / \mathrm{bbl}$ & 87 & 96 & 110 & 117 & 125 \\
\hline
\end{tabular}




\section{III.II Quantity of Fuel Required}

The Base Case will require 292 thousand tons of diesel ,79 million tons of furnace oil , 9.2 million MMcf of natural gas, 1,621 million tons of coal, and 9.2 thousand tons of $\boldsymbol{U}_{\mathbf{3}} \boldsymbol{O}_{\mathbf{8}}$. The power sector will need the sufficient fuel and infrastructures' to make sure that the fuel supplies and infrastructure will be available to implement the power sector expansion plan. The base case requirement of fuel by its type for Pakistan (year 2011-2030) is shown in Table. 2.

TABLE. 2

\begin{tabular}{|cllllll|}
\hline \multicolumn{7}{|c|}{$\begin{array}{l}\text { Base Case Requirement of Fuel by its Type for } \\
\text { Pakistan }\end{array}$} \\
\begin{tabular}{|l} 
Year \\
2011-2030
\end{tabular} & $\begin{array}{l}\text { NG } \\
\text { (million m3) }\end{array}$ & $\begin{array}{l}\text { NG } \\
\text { (million MMcf) }\end{array}$ & $\begin{array}{l}\text { FO (million } \\
\text { ton) }\end{array}$ & $\begin{array}{c}\text { Thar coal } \\
\text { (million ton) }\end{array}$ & $\begin{array}{l}\text { Dies } \\
\text { (Ton) }\end{array}$ & $\boldsymbol{U}_{\mathbf{3}} \boldsymbol{O}_{\mathbf{8}}$ (Ton) \\
\hline Total & 261,452 & 9.2 & 78.8 & 1,621 & 291,719 & 9,253 \\
\hline
\end{tabular}

\section{III.III Necessary Parameters for Investment and Financial Plan}

The energy sales forecast, the load forecast and the system expansion plan (generation plan) are the key input to the financial plan. The system expansion plan is a least-cost plan to serve Pakistan's load growth and current load over the period 2011 to 2030 . The basic objective for the financial plan is to obtain the financial cost for the power sector over the period of 20 years (2011 to 2030). There are several new hydro projects carried out by the Pakistan government and the thermal projects by the private sector. For development of financial plan, these factors count as summarized below in Table.3:

TABLE.3

\begin{tabular}{|ll|}
\hline Factors (Criteria) & Adopted Values \\
\hline Inflation Rate & $2 \%$ \\
\hline Discount Rate & $10 \%$ \\
\hline Rate of Return & $15 \%$ on Equity \\
\hline Cost of borrowing & $8 \% /$ annum \\
\hline Debt/Equity ratio & $70 \% / 30 \%$ \\
\hline Loan Repayment Period & 10 years \\
\hline Exchange rate & 92 Pakistani Rupee $=1$ \$ US (2011) \\
\hline Asset Life & \\
\hline Thermal Asset Life & 30 years \\
\hline Hydro Asset Life & 50 years \\
\hline
\end{tabular}

\section{III.IV Load Forecast}

Load is forecasted using standard regression methods. It is a forecasting or prediction technique used to forecast loads as discussed in [12]. The load forecast projects the load in both energy and peak demand to 2035 at the country level. The long-term plan includes three scenarios of load. They are peak load, intermediate (base load) and low load. The key inputs to the forecast are total Gross Domestic Product and GDP by sector, Population of the country, number of customers, price elasticity, and including load profiles. Load Profiles include load factor and loss reduction programs. The forecast shows that the load will be six times more of the current demand by 2035, as given below in Table. 4 .

TABLE. 4

\begin{tabular}{|lll|}
\hline \multicolumn{3}{|c|}{ Base Case Load Growth for Pakistan } \\
\hline Base Case & Year - 2011 & Year- 2035 \\
\hline Sales (TWh) & 127 & 738 \\
\hline Generation (TWh) & 176 & 890 \\
\hline Peak Load (MW) & 24,000 & 150,000 \\
\hline
\end{tabular}

A striking result shows that the per capita consumption of the country is expected to increase from 640 $\mathrm{kWh} /$ year to $2,540 \mathrm{kWh} /$ year over the next 25 years. The load forecast at the national level shows that the 
average base load case growth for energy is $8.2 \%$ over the next ten years and then $7.7 \%$ thereafter as shown below in Table. 5 .

TABLE. 5

\begin{tabular}{|lll|}
\hline \multicolumn{3}{|c|}{ Load Forecast Table (Requirement of Generation (Tera Watt Hour)) } \\
\hline Scenarios & Year-2011 & Year-2030 \\
\hline Base Case & 168 & 651 \\
\hline High Growth & 168 & 769 \\
\hline Low Growth & 168 & 501 \\
\hline
\end{tabular}

The preparation of the load forecast is based on energy factors. It doesn't take peak loads in account.

Results of load forecast shows that base case load forecast from $168 \mathrm{TWh}$ rises to $651 \mathrm{TWh}$ in year 2030. In High Growth rate it rises from 168 TWh to 501 TWh(year 2030). As in Low Growth it reaches 769 TWh (Year 2030). In Table. 6, Load is forecasted for peak load in Mega Watt.

TABLE. 6

\begin{tabular}{|lll|}
\hline \multicolumn{1}{|c|}{ Load Forecast Table (Peak Load (MW)) } \\
\hline Scenarios & Year-2011 & Year-2030 \\
\hline Base Case & 24100 & 107481 \\
\hline High Growth & 24100 & 128041 \\
\hline Low Growth & 24100 & 82461 \\
\hline
\end{tabular}

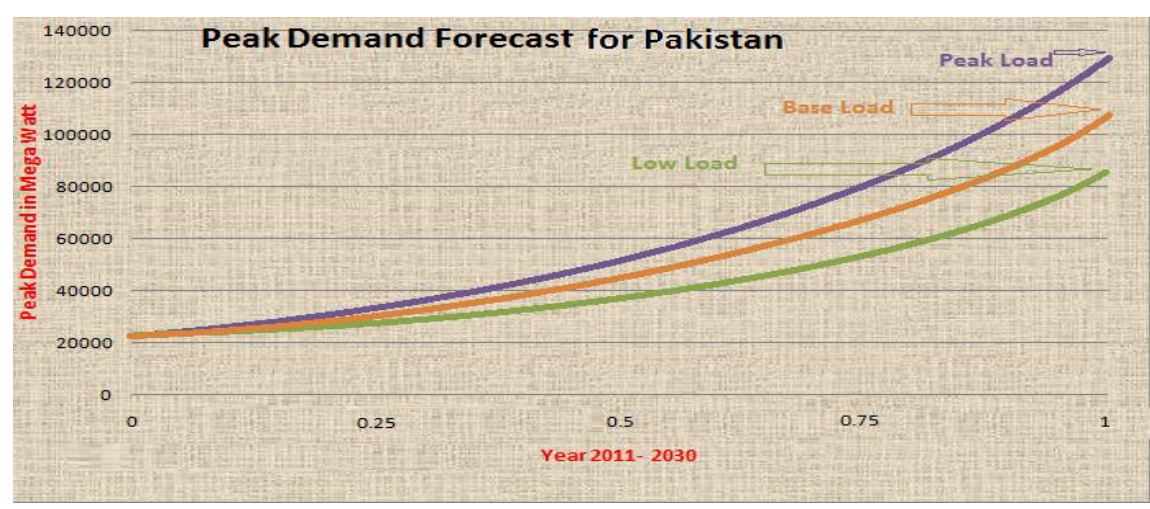

Fig.7 Peak Demand Forecast (year 2011-2030)

The Load Forecast for peak Load in Mega watt determined in Fig. 7, shows the Intermediate (Base) Load of $107481 \mathrm{MW}$ in year 2030. For high load it shows $128041 \mathrm{MW}$ in year 2030. And for low load growth it is $82461 \mathrm{MW}$ in year 2030 .

\section{III.V Parameters for Modeling}

The models for thermal and nuclear plants are described by maximum and minimum capacities to be installed, heat rate at minimum capacity and incremental heat rate between minimum and maximum capacity, Failure probability (forced outage rate), Variable fuel cost, emission rates and plant life.

The models for hydroelectric projects are for run-of-river, daily peaking, weekly peaking and seasonal storage regulating cycle [13]. They are defined by identifying for each project with minimum and maximum capacities, Energy storage capacity of the reservoirs, Energy available per period, Capital investment cost, Fixed operating and maintenance $(\mathrm{O} \& \mathrm{M})$ costs and Plant life. Hydro plants are modeled by specifying installation capacity, Cycle Efficiency, Pumping capacity (for each period defined by user in one year), Generation capacity (for each period), Maximum feasible energy generation (for each period) [8].

Selection of Plants is done on the basis of Screening Curves. It plays vital role in selecting economical power plant. It decides which plant is more economical comparatively to other plant along with its capacity factor. Then it decides the candidate plants (which are to be added in future) to be added in self defined year of expansion. The generation expansion plan is based on satisfying reliability criteria. Loss of Load Probability (LOLP) is the risk that shows insufficient generation to meet the forecasted load demand. By taking in account Fixed Operation and Maintenance Cost, Total Capital Cost and levelized fixed charge rate, we find Annualized Fixed Cost by (1), given below:

Annualized Fixed Cost $=($ Total Capital Cost $*$ levelized Annual Fixed Charge rate $)+($ Fixed Operation and Maintenance Cost). 
Further we determine Variable cost with the help of (2), given below. It requires Annual average heat rate, Fuel cost, Variable Operation and Maintenance Cost.

Variable Cost $=($ Annual Average heat rate $*$ Fuel cost $)+($ Variable Operation and Maintenance Cost $)$.

In last we construct the Screening Curve for each Power Plant with different values of Capacity Factors taken continuously between 0 and 1 . Through (3), we determine total cost and it helps in generating a screening curve for each plant.

Total Cost $=($ Annualized Fixed Cost $)+($ Variable Cost $*$ Capacitor Factor * Hours/yr $)$

We repeat the above process for all the power plants to get screening curve for individual power plant to be added in generation mix supply. And in such a way we compare the Annualized Fixed Cost (\$/KWyear) at operated Capacity Factor.

\section{Results And Conclusion}

The results generated by different modules are discussed below in detail.

\section{I Screening Curve}

The screening curves for different power plants are plotted in excel as shown in Fig. 4 below:

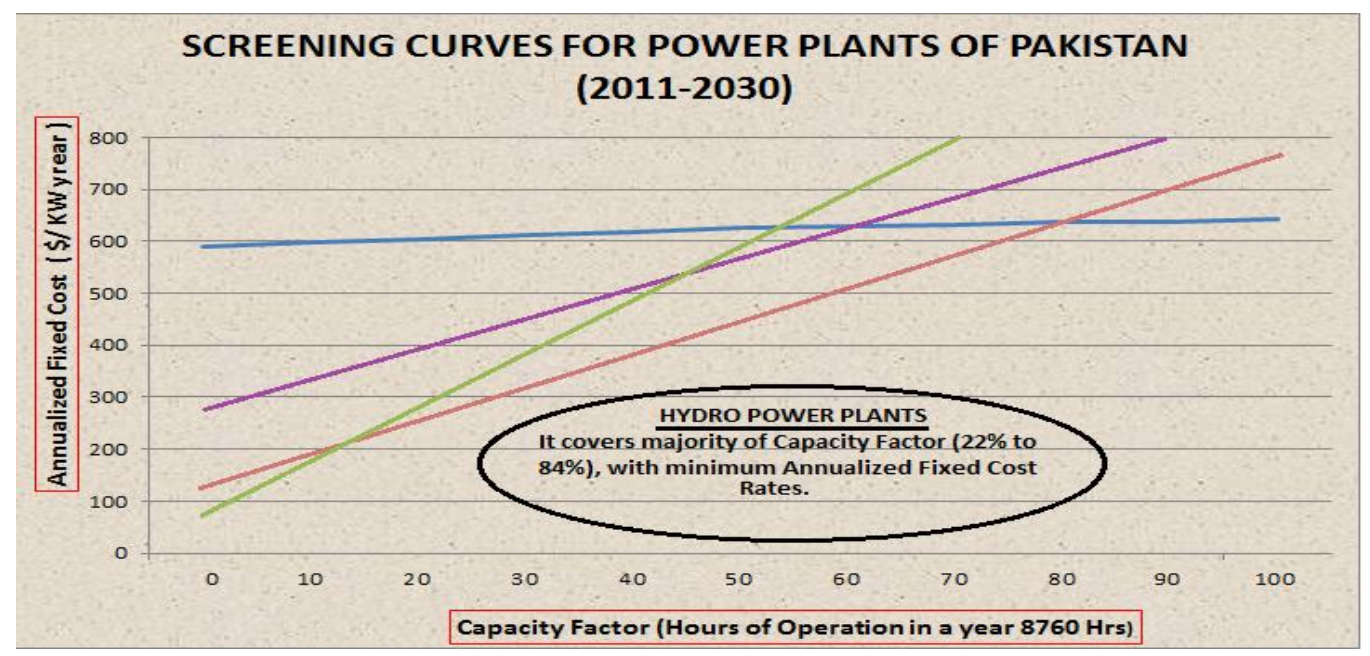

Fig.8. Screening Curves for each power plant Vs Capacity Factor

“ " this line shows the Screening Curve for Combined Cycle power plants.

“ " this line shows the Screening Curve for Steam Turbine (Thar Coal) with Annualized fixed cost of $275.5 \$ / \mathrm{KW}$ yr (Taking Capacity Factor $=0$ ) and Total Cost is $875.6 \$ / \mathrm{KWyear}$ (for Capacity Factor = $1)$.

“ " this line shows the Screening Curve for Nuclear power plant with Annualized fixed cost of $540 \$ / \mathrm{KW}$ yr (Taking Capacity Factor $=0$ ) and Total Cost is $643 \$ / \mathrm{KWyr}$ (for Capacity Factor $=1$ ).

" " this line shows the screening curve for Gas Turbine with Annualized fixed cost of 76.3 \$/ KW yr (Taking Capacity Factor $=0$ ) and Total Cost is $1058.2 \$ / \mathrm{KWyr}$ (for Capacity Factor $=1$ ).

“ $\varnothing$ " this circle shows the region and area for Hydro power plants. Its minimum Annualized cost starts from 22.69 \$ KWyear and reaches to maximum Annualized Fixed Cost of 309.35 \$/KWyr.

In Table.7, different power plants cost is evaluated at several capacity factors.

\begin{tabular}{|c|c|c|c|c|c|c|c|c|}
\hline & $\begin{array}{l}\text { Capacity } \\
\text { Factor }\end{array}$ & $\begin{array}{l}0 \% \\
(0.1)\end{array}$ & $\begin{array}{l}20 \% \\
(0.2)\end{array}$ & $\begin{array}{l}40 \% \\
(0.4)\end{array}$ & $\begin{array}{l}60 \% \\
(0.6)\end{array}$ & $\begin{array}{l}70 \% \\
(0.7)\end{array}$ & $\begin{array}{l}80 \% \\
(0.8)\end{array}$ & $\begin{array}{l}100 \% \\
\text { (1) }\end{array}$ \\
\hline \multicolumn{9}{|l|}{$\begin{array}{l}\text { Power Plants } \\
\text { (\$ /KW year) }\end{array}$} \\
\hline $\begin{array}{l}\text { Gas } \\
\text { Turbines }\end{array}$ & & 76.3 & 269.8 & 463.9 & 651.1 & 743.4 & 839.5 & 1058.2 \\
\hline $\begin{array}{l}\text { Steam } \\
\text { Turbines(Coal) }\end{array}$ & & 275.5 & 396.4 & 531.7 & 647.8 & 697.3 & 758.2 & 875.6 \\
\hline $\begin{array}{l}\text { Combined } \\
\text { Cycle }\end{array}$ & & 125.5 & 264.6 & 379.9 & 507.4 & 582.7 & 622.9 & 749.1 \\
\hline Nuclear & & 595.8 & 605 & 616.8 & 627.3 & 629.8 & 634.1 & 643.6 \\
\hline $\begin{array}{l}\text { Hydro (served for } \\
\text { peak loads) }\end{array}$ & & & 18.3 & 304.1 & & & & \\
\hline
\end{tabular}


As it is very much evident from the above Fig. 8 of Screening Curves that hydro power plants are more economical than thermal power. As they have no fuel costs and other charges except of Operation and Maintenance Costs. But its Capacity Factor is constrained due to its seasonal availability. Hydro power plants store the water through pumped storage phenomenon, but shortage of rain would result in power shortfall [14]. And thus leading to Loss of Load Probability (LOLP) criteria [10]. And the plant would be unable to meet the power demand. And the supply should meet the demand is the paramount theme. The basic objective of the least-cost planning is to find new addition of plants through the optimal generation mix supply that will constantly supply the energy demand over the entire planning period of (Year 2011 to Year 2030). A broadened generation mix supply is prepared with the help of screening curves. It emphasizes on the selection of plant on the priority basis for the indigenous resources. Thus providing stability in costs for long durations. Currently, the primary source of energy supply has come from natural gas, oil, hydro and nuclear.

\section{Screening Curves Vs Load Duration Curves}

The Load Duration Curve generated in LoadSys module with Fourier Approximation Method is normalized between " $0-1$ ". The graph of Normalized Load Duration Curves Vs Capacity Factor describes peak load, Intermediate load and low load [12]. Peak Load amplitude is defined from the values " 0.75 to 1 " along yaxis and Capacity Factor is between (0 to 0.1) along x-axis in Fig. 9. Intermediate Load amplitude is defined from " 0.35 to 0.74 " along y-axis and Capacity Factor is between ( 0.11 to 0.4 ) along $x$-axis as seen in Fig. 9. Low Load amplitude is defined from " 0.21 to 0.34 " along y-axis and Capacity Factor is between ( 0.41 to 1$)$ along $\mathrm{x}$-axis as seen in Fig. 9.

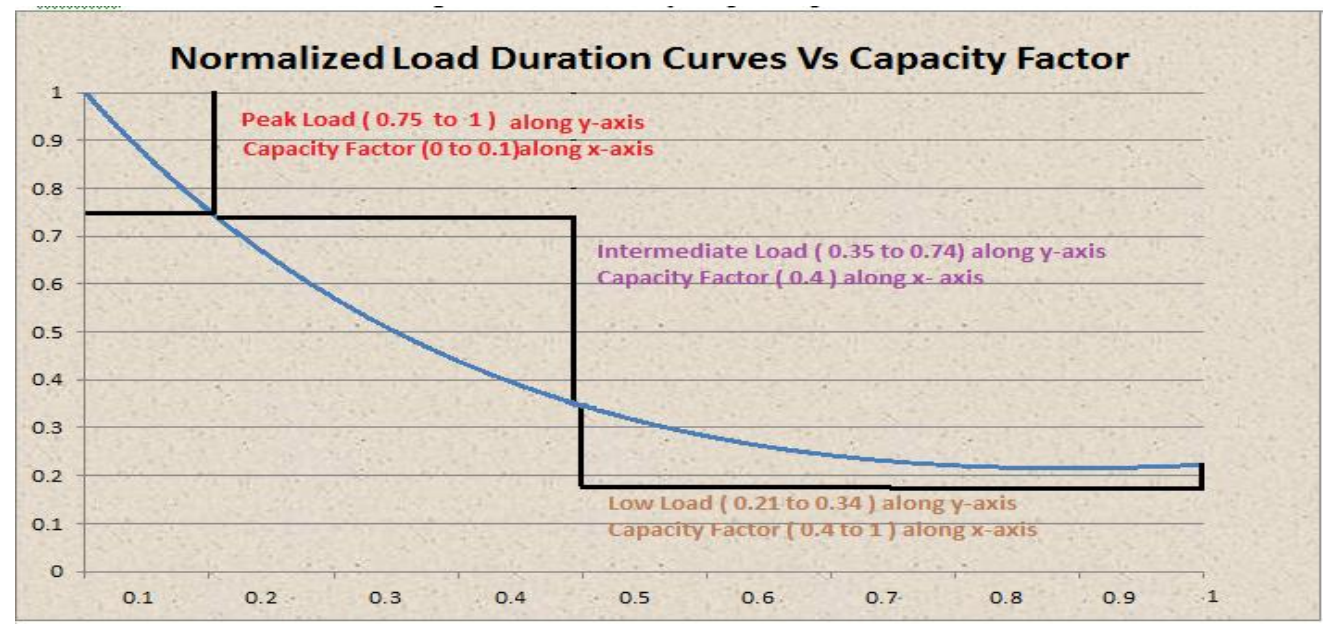

Fig.9. Normalized Load Duration Curves Vs Capacity Factor

155 MW Gas Turbines are also good option for peak loads with capacity factor less than $18 \%$ ). 707 Mega Watt Combine Cycle Power plants were economical between capacity factors from $17 \%-80 \%$. And steam turbine of $600 \mathrm{MW}$ using Thar coal was also one of the candidate plants (to be added in future) for generation expansion., as to promote indigenous energy resources. But after certain time(as ending time defined for peak load), the exuberant usage of fuel in power plants give rapid rise to screening curve of Gas Turbine. As fuel costs are very high, which leads to increase in $\$ / \mathrm{KWh}$ along the capacity factor. So if we run the Gas Turbine power plants with expensive fuel, won't be any more good option. As peak loads are for shorter period and we can afford the fuel costs. And the plant initial installation costs (Annualized Fixed Cost) are less. Nuclear plants were best at operating capacity factor above $80 \%$. But it is prudent that Hydro power plants are exquisitely best for Peak Loads with attaining low Capacity Factor.

\section{Generation Mix Supply For Pakistan (Year 2030)}

The integrated Generation Mix Supply shows that almost 100,000 MW generation capacity needs to be installed to meet the load growth and to replace the 6,954 $\mathrm{MW}$ of retiring plants. The utmost changes in the generation mix are the less thermal power plants are added which are based on oil. Similarly, Gas based power plant generation will decrease from $31 \%$ to $11 \%$. And the coal will replace the oil and gas based generation will be to a large extent replaced by Thar coal based plants. Also renewable energy would provide up-to $7400 \mathrm{MW}$ of power. The Generation Mix Supply for Pakistan (year 2011-2030) is given below in Table. 8 and Fig. 10. 
TABLE. 8

\begin{tabular}{|l|}
\multicolumn{1}{|c|}{ Optimized Least Cost Generation Expansion for Base } \\
Case of Pakistan
\end{tabular}

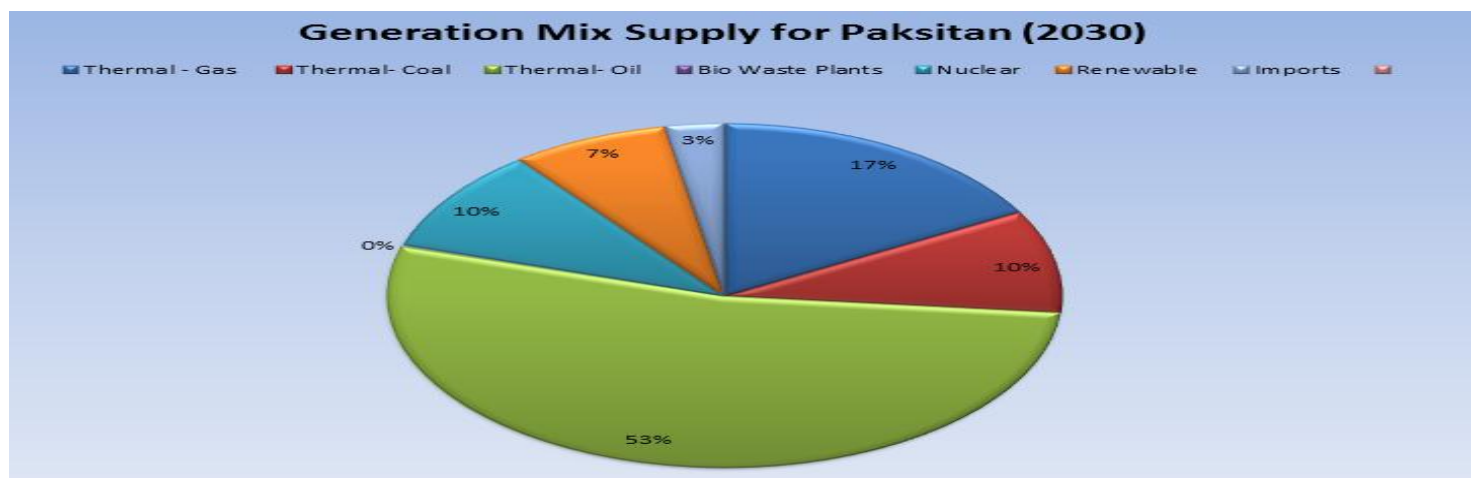

Fig.10 Generation Mix Supply for Pakistan (year 2030)

The optimized least-cost generation plan for Base Case is shown in below Table 10. It predicts that the net generating capacity will exceed the peak demand of the system in 2030 .

\section{Investment And Production Costs}

This plan is optimized to ensure the lowest production and investment cost while satisfying reliability criteria targets.

TABLE. 9

\begin{tabular}{|ll|}
\hline $\begin{array}{l}\text { Investment and Production Costs for Pakistan ( } \\
\text { SUS Million) }\end{array}$ & \multicolumn{1}{c|}{$\begin{array}{c}\text { Year 2011-2030 } \\
\text { Total Cost in \$ US Million }\end{array}$} \\
\hline Investment Costs & 191402 \\
\hline Fuel Costs & 290992 \\
\hline Operation and Maintenance Costs & 38309 \\
\hline Un-served Energy Charges & 34,189 \\
\hline Total Generation Costs & 554,892 \\
\hline
\end{tabular}

Total Investment and Production Costs of Pakistan for 20 years is 554,892 US Million dollars. It includes Investment Costs up-to 19,1402 US Million Dollars, Fuel Costs up-to 290,992 US Million Dollars, Operation and Maintenance costs are 38309 US Million Dollars. And energy not served costs are 34,189 US Million Dollar. As Energy Not Served Shows (energy not served) shows the expected harm to the economy of the country energy demand is not fulfilled. This cost is modeled in WASP through a quadratic function as discussed in [6].

If we define Discount Rates at $10 \%$ in the DYNPRO module, the total generation cost would be reduced to US \$248,844 Million than US \$ 647,657 Million. The Discount on fuel and construction material and maintenance is provided in the form of subsidies and reduced tariff rates by Government. The average annual investment outlay is assessed to be over 11 billion US Dollar.

The result depicts that the cost of generation of plants for thermal projects are significantly higher as compared to the cost of hydro generation. The cost of generation for the hydro power plants is equal to 6.87 cents/kWh for entire period, while thermal generation costs are equal as 13.1 cents $/ \mathrm{kWh}$. The main reason of high thermal generation cost is due to their fuel rates. For hydro plants the production cost is extremely low due to the absence of any fuel requirements emphasis on the development of hydro power generation would be a prudent strategy in order to keep the generation cost low. Giving priority to Hydro power plants would keep tariff rates stable. 
TABLE. 10

\begin{tabular}{|c|c|c|}
\hline \multicolumn{3}{|c|}{$\begin{array}{l}\text { Hydro and Thermal Generation Expansion Optimized Least Costs for Pakistan } \\
\text { Year (2011-2030) } \\
\text { (Million US Dollar\$) }\end{array}$} \\
\hline & $\begin{array}{l}\text { Without Discount Rates } \\
\text { Year } 2011-2030\end{array}$ & $\begin{array}{c}\text { With Discount Rates at } 10 \% \\
\text { Total Costs } \\
\text { Year } 2011-2030\end{array}$ \\
\hline $\begin{array}{l}\text { Hydro-Capital } \\
\text { Expenditures }\end{array}$ & 85407 & 37057 \\
\hline $\begin{array}{l}\text { Hydro Operational } \\
\text { Expenditures }\end{array}$ & 12068 & 3473 \\
\hline $\begin{array}{l}\text { Thermal Capital } \\
\text { Expenditure }\end{array}$ & 148015 & 59321 \\
\hline $\begin{array}{l}\text { Thermal Operational } \\
\text { Expenditures }\end{array}$ & 37550 & 12164 \\
\hline $\begin{array}{l}\text { Thermal Fuel } \\
\text { Expenditures }\end{array}$ & 364617 & 136829 \\
\hline Total Generation cost & 647657 & $248 \quad 844$ \\
\hline
\end{tabular}

Its the most significant model for hydro and thermal power plants generation system achieved with the help of WASP-IV. The generation mix supply is prepared with certain constraints including fuel, place availability, political involvements, environmental pollutants, As the population rises, there is need to install more power plants. So this research helps to meet the shortage of electricity demand in future. And it accomplishes least cost expansion for Pakistan (2011-2030). The selection and addition of plants is done on the basis of screening curves. Moreover Screening Curves gives imminent knowledge about the most feasible power plant when operated at different capacitor factors. The analysis helps us in selecting the most economical plants. As efficient modeled system plays vital role in the country's economical development.

\section{Acknowledgements}

I am deeply indebted to all of my respected teachers in completion of this research paper. My beloved teachers like Professor Dr. I.M Qureshi, Assistant Prof. Atiq-ul-Inam, Sr. Chief Energy Specialist. Engr. Muhammad Latif, Assistant Prof. Dr. Ihsan ul Haq, Prof. Dr. Ghulam Yasin Chohan, Assistant Prof. Hassan Humayun and Assistant Prof. Naveed Ahmed provided continuous help, stimulating suggestions, knowledge, time and encouragement during all the period of my research. Without their support, it was impossible to achieve my desired goal. It was exquisitely good learning experience while working under them.

\section{References}

[1] Ishan Sharan and R. Balasubramanian, "Integrated generation and transmission expansion planning including power and fuel transportation constraints", ELSEVIER, Energy Policy, Vol. 43, Issue 1, PP. 275-284, April 2012.

[2] A. G. Kagiannas, D. T. Askounis, and J. Psarras, "Power generation planning:A survey from monopoly to competition”,॥ Int. J. Elect. Power Energy Syst. vol. 26, no. 6, pp. 413-421, 2004.

[3] ESB National Grid, All-Island Market modeling programme, all island modeling assumptions, model version 0.1 , November 2005.

[4] Department of Communications, Marine and Natural Resources and the Department of Enterprise, Trade and Investment, All Island Grid Study, 2008.

[5] H. Daly and B. P. Ó Gallachóir, Modelling private car energy demand using a technological car stock model, Transportation Research Part D Transport and Environment (In Review), 2010.

[6] Internatinal Atomic Energy Agency, - Wien Automatic System Planning (WASP) package - A computer code for power generating system expansion planning, version WASP-IV user's manual,॥ IAEA, Vienna, 2006.

[7] R. Bellman, Dynamic Programming. Princeton, 1957.

[8] S.M. Moghaddas Tafreshi, A. Saliminia Lahiji and J. Aghae,Al rabiee , "Reliable generation expansion planning in pool market considering power system security", ELSEVIER, Energy Conversion and Management, Vol. 54, Issue 1, PP. 162-168 February 2012.

[9] Morgan Bazilian, Patrick Nussbaumer, Hans-Holger Rogner, Abeeku Brew-Hammond, Vivien Foster, Shonali Pachauri, Eric Williams, Mark Howells, Philippe Niyongabo, Lawrence Musaba, Brian Ó Gallachóir,Mark Radkaj and Daniel M. Kammen, "Energy access scenarios to 2030 for the power sector in sub-Saharan Africa", ELSEVIER, Utilities Policy, Vol. 20, Issue 1, PP. 116, March 2012.

[10] L.A.F. Manso and A.M. Leite da Silva, "Probabilistic criteria for power system expansion planning", ELSEVIER, Electric Power Systems Research, Vol. 69, Issue 1, PP. 51-58, April 2004.

[11] J. Santisirisomboon, "Least cost electricity generation options based on environmental impact abatement", Environmental Science Policy (2003), Vol. 6, Issue: 6, PP. 533-541, January 2003.

[12] A. Hainoun, "Construction of the hourly load curves and detecting the annual peak load of future Syrian electric power demand using bottom-up approach", ELSEVIER, International Journal of Electrical Power \& Energy Systems, Vol. 31, Issue 1, PP. 1-12, January 2009.

[13] G. Rabensteiner, "Long-term expansion planning for hydrothermal electric power systems", International Journal of Electrical Power \& Energy Systems, Vol. 7, Issue 4, PP. 225-228, October 1985.

[14] Ibrahim Yüksel, "Hydropower in Turkey for a clean and sustainable energy future", ELSEVIER, Renewable and Sustainable Energy Reviews", Vol. 12, Issue 6, PP. 1622-1640, August 2008.

[15] A.M. Foley, B.P. Ó Gallachóir, J. Hur, R. Baldick, E.J. McKeogh, “Astrategic review of electricity systems models", Energy, In Press, Corrected Proof, Available online 15 May 2010.

[16] A. Tuohy, Operational and Policy Issues in Carbon Constrained Power Systems, PhD Thesis, University College Dublin, 2009.

[17] Pakistan Energy Year book 2011, published by Hydrocarbon Development Institute of Pakistan, 23 rd April, 2011.

[18] www.iea.org

[19] www.isgs.pk

[20] http://www.eia.gov/

[21] www.nationmaster.com 